\title{
Seiching Induced by Bichromatic and Monochromatic Wave Conditions: Experimental and Numerical Analysis in a Large Wave Flume
}

\author{
Luigia Riefolo $^{1, *(D)}$, Pasquale Contestabile ${ }^{1,2}$ and Diego Vicinanza 1,2,3 (D) $^{\text {(D) }}$ \\ 1 Department of Engineering, University of Campania “Luigi Vanvitelli”, via Roma, 29, \\ 81031 Aversa (Caserta), Italy; pasquale.contestabile@unicampania.it (P.C.); \\ diego.vicinanza@unicampania.it (D.V.) \\ 2 Inter-University National Consortium for Marine Sciences (CoNISMa), Piazzale Flaminio, \\ 9-00196 Roma, Italy \\ 3 Stazione Zoologica Anton Dohrn, Villa Comunale, 80121 Napoli, Italy \\ * Correspondence: luigia.riefolo@unicampania.it ; Tel.: +39-081-5010245
}

Received: 27 April 2018; Accepted: 1 June 2018; Published: 6 June 2018

\begin{abstract}
This paper describes a set of spectral and eigen analysis in order to identify seiche generation from a large-scale laboratory dataset. The experiments were performed in the large-scale "Canal d'Investigació i Experimentació Marítima" wave flume at the Universitat Politècnica de Catalunya in Spain. Erosive and accretive wave regimes have been analyzed, including monochromatic waves and bichromatic wave groups with different bandwidths. Each test started with approximately the same underlying beach conditions. Video runup measurements are also used to better understand the role of the bandwidth in the generation of swash oscillation. Some evidence of the influence of low frequency waves on runup and sediment transport pattern is found. Good agreements between eigenmode families for volume flux and sediment volume variations are also shown.
\end{abstract}

Keywords: spectral analysis; low frequency; bichromatic waves; monochromatic waves; bandwidth; eigenvalues

\section{Introduction}

Real ocean waves can be described as a superposition of many sinusoidal waves with different wavelengths, amplitudes, initial phases and propagation directions, by assuming that the wave process is stationary. They are represented by adopting two widely used wave spectrum models namely Pierson-Moskowitz (P-M) and Joint North Sea Wave Project (JONSWAP), respectively [1,2]. The P-M spectrum model is based on long-term observations of the wave fields in the North Sea [1]. On the other hand, JONSWAP spectrum model is based on the observations obtained along a profile in the North Sea westward from the Sylt Island (Westerland, Germany). JONSWAP spectrum in comparison with the P-M spectrum has an advantage including the effect of limited wind fetch and water depth [2]. Furthermore, in terms of a wave spectrum, the wave-wave interactions can be formulated, according to Hasselmann [3].

As known, there are some waves in the ocean that resemble what is considered to be a superimposition of sinusoidal waves. Severe waves, generated by a distant storm, tsunami or solitary waves, are some examples. Such waves can be surprisingly regular, but never pure sine waves. Behind the common reference to the "random" sea state, there are other models of sea surface in which the full description of the surface motion is approximated by different mathematical formulations. Among them, a very powerful tool is represented by bichromatic wave group of full modulation. The main 
characteristics of such multi-component wave patterns, constituted by two superimposed sinusoidal waves, are:

- the envelope travels unchanged;

- each component travels with its own phase velocity, in accordance with the dispersion relation.

The model is a simple but effective way to analyze the beat pattern, also known as wave group, as well as the generation of Low Frequency Waves (LFWs). Such waves are important not only for the additional wave induced velocity and long wave effect on the short wave hydrodynamics [4,5], but also for the formation of standing waves, or a cross-shore and longshore nodal structure (e.g., Holman and Bowen [6]). Bichromatic wave groups, in fact, were used in laboratory work specifically focused on surf-beat-generation mechanisms [7,8] or on breakpoint modulation [9-11]. More recently, cross-shore long wave generation on relatively steep (1:10) and mild (1:40) slopes were studied by Dong [12]. The breakpoint forced long waves were observed primarily on the steep slope, also according to Baldock et al. [13], for which much of the incident wave grouping remains within the swash zone and at the still water shoreline. Furthermore, at the incident wave group frequency, the shoreline motion is modulated. They also found that the swash oscillations, driven by the bichromatic wave groups on the 1:10 slope, are largely dominated by low-frequency motions.

On the other hand, for a mild slope beach, Dong [12] found that the released bound long waves are the major contributors to the free long waves. This is clearly in line with the conclusion drawn by Madsen et al. [14,15] in discussing surf beat and swash oscillations induced by bichromatic wave groups and irregular waves on gentle beach slopes using a Boussinesq-type wave model. According to their findings, the shoreline motion consists of a significant low-frequency component at the group frequency and individual swash of the primary waves.

Padilla and Alsina [16] investigated the influence of the frequency bandwidth on the propagation of bichromatic wave groups over a constant 1:100 beach slope. The authors found that in the low frequency domain a larger growth of the incident bound long wave for broad band wave conditions is detected.

Numerical modeling $[17,18]$ has been used to investigate the role of surf beat. In particular, long wave terms were included and excluded from a numerical model and the predicted morphology compared with a measured beach profile related to random wave tests. Therefore, considering long waves in the model, the results showed a smoothed bar, reduced bar height and moved bar crest seaward, and also less erosion in the inner surf zone. Jannat and Asano [19] adapted a numerical model from Kobayashi et al. [20] to investigate sediment transport under long waves. The long waves induced small changes in the surf zone, and larger changes in the Swash Zone (SZ), where long waves have maximum amplitude. According to Halfiani and Ramli [21], numerical results on the deformation of bichromatic wave groups based on the third order side band solution of Benjamin-Bona-Mahony equation showed that nonlinear effects determine deformation of the wave groups.

Both free and forced long waves occur in the nearshore zone and surf zone, but little previous work has examined the overall impact of free long waves on the beach evolution. Similarly, direct study of how sediment transport and the erosion or accretion of beaches are influenced and modified by long waves and wave groups is still lacking. In fact, although there have been many investigations on the kinematics of extreme waves in deep water using focused wave groups in wave flumes and basins [22-26], there has been little research on the wave grouping in the nearshore environment $[27,28]$. For repeated wave groups, Borthwick et al. [29] confirm the presence of a low frequency free wave, followed by higher frequency waves of the main group and trailing higher order harmonic waves.

Under random wave conditions in small-scale experiments, Dally [30] observed that seiching influences the final equilibrium profile, smooths the bar-trough morphology and carries sediment higher in the swash zone.

Both bichromatic and random (JONSWAP) waves were used by Brocchini and Bellotti [31] to evaluate and simplify a theoretical model of Shoreline Boundary Conditions to be used as the SZ 
boundary in wave-averaged nearshore circulation models. Although there are insights about the effects of individual long-waves in hydrodynamic and shoreline motion terms, few direct experiments have investigated the influence of free long waves and wave groups on surf and swash zone morphodynamics. Their influence appears significant, as shown by Baldock et al. [32,33], with free long waves tending to reduce offshore sediment transport or increase onshore sediment transport. On the other hand, bichromatic wave groups resulted in much greater erosion than equivalent monochromatic waves. Furthermore, the small-scale of the experiments (water depth $0.5 \mathrm{~m}$, wave height $0.05 \mathrm{~m}-0.1 \mathrm{~m}$ ) meant that scale-effects could have been significant in influencing the results. The complexity of the problem suggested the need to obtain and operate on data acquired through laboratory investigations at a larger scale. The present study is based on high quality data from tests carried out in a large wave flume, as part of the SUSCO (Swash zone response Under grouping Storm Conditions) experiment within the Hydralab III program [34]. The scale of experiment is arbitrary. Froude similarity is normally considered in open-channel hydraulics, where friction effects are negligible. However, in movable bed experiments, the scaling law should take into account the size of model sediments. In particular, a scaling law related to the dimensionless fall velocity must be considered. Scale effects are always present but are minimized by using a large wave flume.

The main aim is to investigate swash zone under storm conditions. A low frequencies analysis under bichromatic and monochromatic wave conditions has led to important considerations on resonant interactions detected in the wave flume and related to swash zone hydrodynamics.

\section{Model Setup and Experimental Program}

The tests were carried out at the Universitat Politècnica de Catalunya (UPC) in the Canal d'Investigació i Experimentació Marítima (CIEM) large-scale wave flume. The facility has a water depth at the toe of the paddle of about $2.5 \mathrm{~m}$, a length of $100 \mathrm{~m}$ and a width of $3 \mathrm{~m}$. The medium sediment size and measured sediment fall velocity were $0.25 \mathrm{~mm}$ and $34 \mathrm{~mm} / \mathrm{s}$, respectively.

Considering a horizontal coordinate $(\mathrm{x})$ moving from the wave paddle toward the shoreline, the sandy beach profile consisted of the following sections (Figure 1):

- from $\mathrm{x}=31$ to $37 \mathrm{~m}$, a 1:20 slope plane beach;

- from $x=37$ to $42 \mathrm{~m}$, a plane bed;

- from $x=42$ to $100 \mathrm{~m}$, an overall mean beach gradient of approximately 1:15.

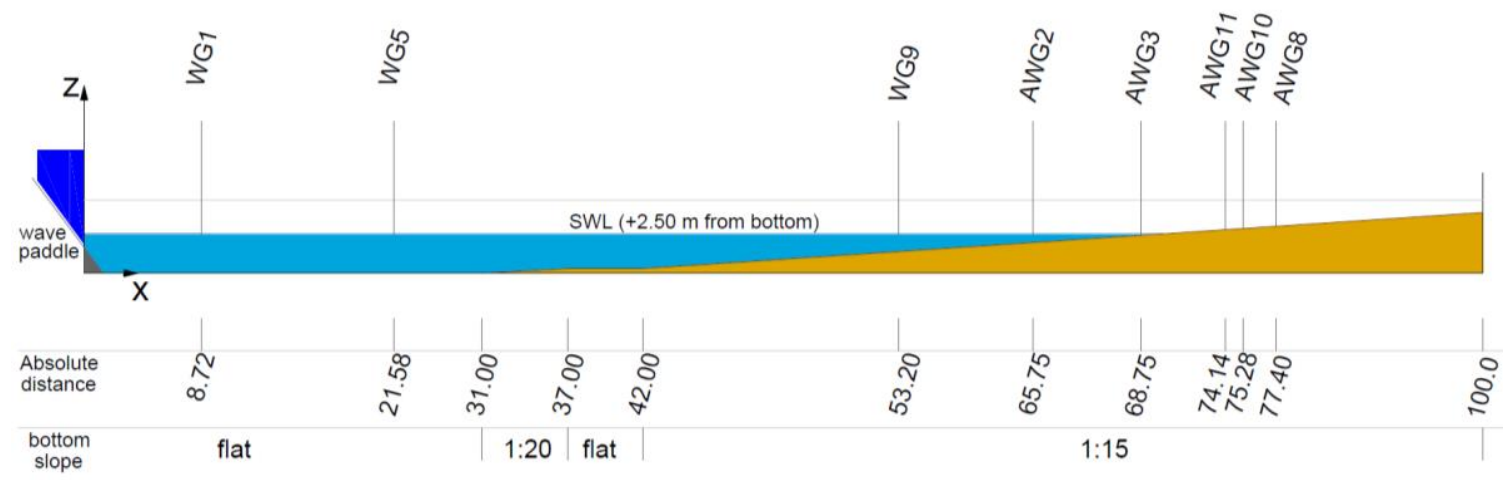

Figure 1. Universitat Politècnica de Catalunya (UPC) wave flume, longitudinal cross-section, detail of wave gauges (WG), acoustic wave gauges (AWG) location in the most active beach part and still water level (SWL) position. All measures are in $\mathrm{m}$.

The profile represents a sand beach in the UPC wave flume that has been investigated previously (e.g., $[11,35])$. In particular, the 1:15 slope of the inner surf and swash zone were deliberately chosen to be far enough from an equilibrium profile, taking into account underlying beach conditions and tested 
sea states. It is worth noting that the slope represents the theoretical limit between steep and moderate beaches and, therefore, represents a transient swash regime. Such beach slope, moreover, has been investigated by several laboratories [36-39] and field studies (e.g., [40]).

The wave generator system consisted of a wedge type wave paddle, particularly suited for intermediate-depth waves, and a control system implemented by Aalborg University, which accounts for reflection. The absorbing system is particularly functional for higher reflection conditions, i.e., over $30 \%$. Obviously, due to stroke limitations by the paddle, very long waves cannot be effectively adsorbed. The experimental program was divided into two test series, erosive and accretive, respectively. Within each series, a number of different wave cases with identical energy level and energy flux were run, including regular monochromatic and bichromatic waves including bound long waves. Therefore, the cases analyzed here are monochromatics and bichromatics wave conditions, both in erosive and accretive cases. The tests were composed of six steps of 24 min duration. Hence, wave generation was halted and restarted every step duration. On the basis of previous experiments in the CIEM flume and of the typical erosion/accretion threshold criteria based on the relative fall velocity, wave conditions were chosen as likely to be erosive or accretive for the monochromatic conditions. Therefore, the final profiles and net sediment transport are consistent with these initial estimates. Case ME represents the monochromatic control conditions for the erosive test series, with $\mathrm{H}=0.37 \mathrm{~m}, \mathrm{~T}=3.7 \mathrm{~s}$ at the wave paddle; the profile evolution for the other erosive wave cases are therefore compared to that for case ME. Case MA is the equivalent monochromatic control case for the accretive test series, with $\mathrm{H}=0.16$ $\mathrm{m}$ and $\mathrm{T}=4.9 \mathrm{~s}$ at the wave paddle.

Four fully modulated bichromatic wave trains were generated, with the intention that each case would have the same theoretical root mean square wave height (and mean energy flux) as its corresponding monochromatic wave. Cases BE_1 and BE_2 generate erosive conditions, and are paired with case ME. Cases BA_1 and BA_2 are paired with case MA and give accretive conditions. The bandwidth of each pair of bichromatic waves is different, and is defined by the frequency difference between the two primary short waves within the group. The specific frequencies were chosen so that the mean energy flux of the pairs of wave trains flux was the same as the corresponding monochromatic waves.

The summary of the experimental program for such tests is reported in Tables 1 and 2. The reader is referred to Vicinanza et al. [34] for further details.

Table 1. Wave characteristics for accretive conditions.

\begin{tabular}{cccc}
\hline Test & H (m) & T (s) & Wave Type \\
\hline MA & 0.160 & 4.9 & Monochromatic \\
\hline \multirow{2}{*}{ BA_1 } & 0.160 & 6.6 & Bichromatic \\
& 0.160 & 5.4 & Bichromatic \\
\hline \multirow{2}{*}{ BA_2 } & 0.160 & 7.1 & \\
\hline
\end{tabular}

Table 2. Wave characteristics for erosive conditions.

\begin{tabular}{cccc}
\hline Test & H (m) & T (s) & Wave Type \\
\hline ME & 0.370 & 3.7 & Monochromatic \\
\hline \multirow{2}{*}{ BE_1 } & 0.260 & 3.9 & Bichromatic \\
& 0.260 & 3.5 & \\
\multirow{2}{*}{ BE_2 } & 0.260 & 4.2 & Bichromatic \\
\hline
\end{tabular}

Prior to running each wave condition, the bathymetry was manually reshaped and then compacted by running $10 \mathrm{~min}$ 'smoothing' wave condition (random waves with $\mathrm{Hs}=0.2 \mathrm{~m}$ and 
$\mathrm{Tp}=6 \mathrm{~s}$ ) in order to obtain almost the same initial profile (Figure 2). In fact, the following were measured:

- maximum vertical variations of $10 \mathrm{~cm}$ within the range $-0.5<\mathrm{z}<0.5 \mathrm{~m}$;

- maximum vertical variations of $25 \mathrm{~cm}$ along the whole profile were measured.

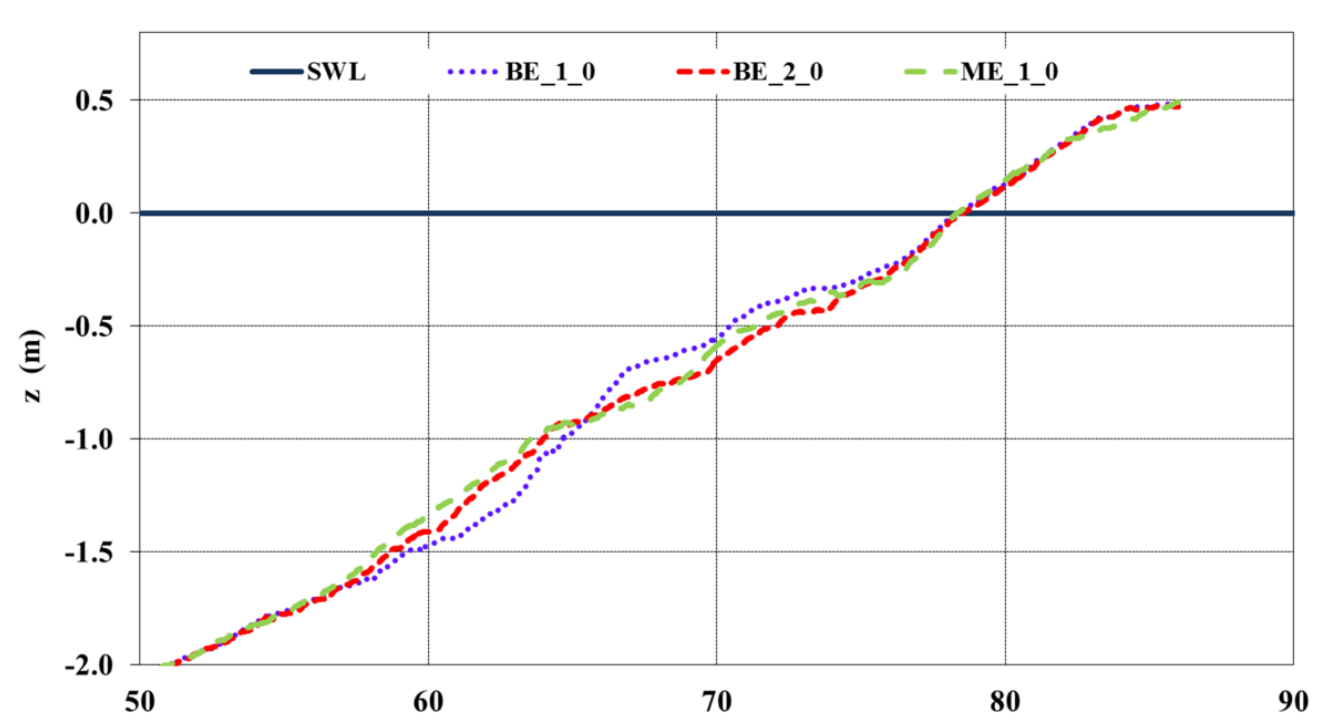

a)

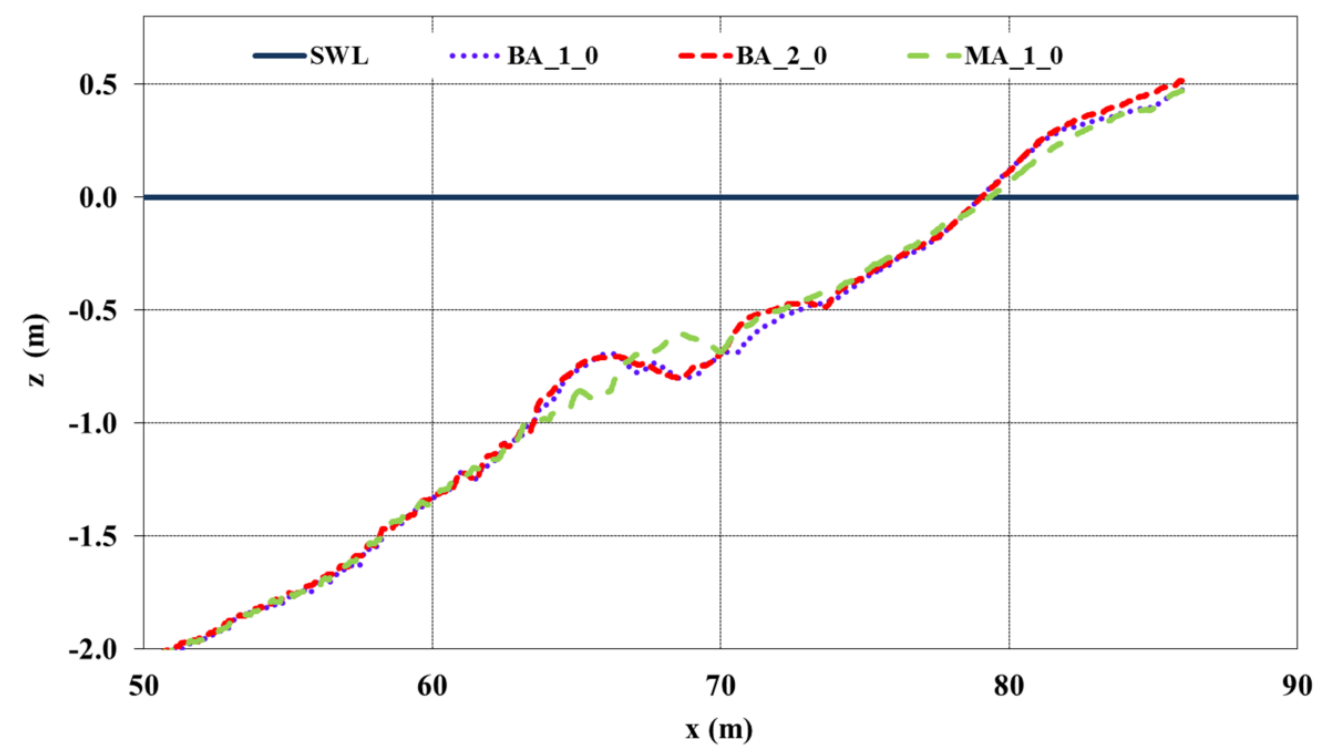

b)

Figure 2. Initial beach profiles: (a) for erosive tests; (b) for accretive tests. Still water level SWL (dark blue line), BE_1_0 and BA_1_0 profiles (dashed blue lines), BE_2_0 and BA_2_0 profiles (dashed red lines) and ME_1_0 and MA_1_0 profiles (dashed green lines) are shown.

The beach evolution along the centerline of the wave flume was measured with a semi-automatic mechanical bed profiler that measures both the sub-aerial and sub-aqueous beach elevation over a range of up to $3 \mathrm{~m}$. The profiler consists of a $0.2 \mathrm{~m}$ diameter wheel on a pivoting jib of length $3 \mathrm{~m}$, which is mounted on a carriage that moves at constant velocity above the flume. A software program was used to convert the wheel rotations and the angle of the jib to distance and elevation above a reference level. When the paddle was operating, the profiler's carriage was in a resting position close to the edge of the beach, and it was used as support for a digital camera. 


\section{Methods}

In the present paper, the hydrodynamic analysis focusses on:

- Seiching identification;

- Runup estimation.

In particular, two complementary sets of analyses have been carried out for seiching study: a spectral and an eigen analysis. Runup, instead, has been measured by using a digital camera records processing.

The dataset treated in this work concerns the first step for every wave condition. As aforementioned, each test commenced with approximately the same initial profile. Therefore, the influence from morphodynamic feedback during the measurements can be considered unimportant, allowing for determining reliable observations of hydrodynamic response in terms of LFW also in movable bed experiments.

\subsection{Seiching Identification}

\subsubsection{Spectral Analysis}

The spectral analysis related to the water surface elevation for all the wave conditions has been carried out in order to analyze the low frequencies.

The power spectral density represents the momentum that corresponds to specific frequencies. A larger amplitude is defined by a higher momentum or spectral density [41]. Accordingly, in order to perform the spectral analysis for each studied test, a Fast Fourier Transform (FFT) is used through MATLAB $^{\mathrm{TM}}$ software (2017b, The MathWorks, Inc., Natick, MA, USA). In particular, a time window equal to the duration of the first step ( $24 \mathrm{~min}$ ) has been analyzed without any filtering applied. The analysis has been conducted in order to ensure wave frequencies aligned with FFT bins. First, the spectral peak at low-frequencies range and harmonics are detected. Consequently, the identified peaks are brought into comparison with the wave modes provided by the eigen analysis, as illustrated in the following section.

\subsubsection{Eigen Analysis}

In order to investigate if the long waves activities are due to or strongly affected by the resonance of specific frequencies (hereinafter "seiche"), an eigen analysis is required. According to Rabinovich [42], the resonance arises when the dominant frequencies of the external forcing match the eigen frequencies of the wave flume. In particular, in an enclosed basin, seiche is defined as long-period standing oscillation. The resonant (eigen) frequency of the seiche is mainly determined by bottom morphology and overall geometry of the basin. Hence, the set of eigen frequencies, included in the associated modes, is a fundamental property of each basin [42]. The modes are the number of seiche nodes within the system. The period of a seiche with " $n$ " nodes is usually described by the so called Merian's formula [43]. This approach assumes a rectangular basin with a uniform water depth, for which the period can be computed as follows:

$$
T_{n}=\frac{2 L}{n \sqrt{g \bar{z}}}
$$

where $T_{n}$ is the period of a $n$th mode seiche; $L$ is wavelength of the seiche (basin's length); $n$ is the number of nodes/modes of the seiche; $g$ is gravity's acceleration equal to $9.81 \mathrm{~m} / \mathrm{s}^{2}$, and $\bar{z}$ is reference water depth.

Therefore, $T_{n}$ can be referred to as the time that the waveform takes to travel a distance of twice the basin length, due to the oscillation from one end of the wave basin to the other and vice-versa. Clearly, seiches with different modes can take place at the same time in a system. However, only one fundamental oscillation is dominant, as previously seen in Wilson [44]. 
In the following section, the results of the calculated eigenmodes and eigenvalues derived by applying a numerical approach are presented. The used method, according to Kirby et al. [45], provides the family of eigenmodes for measured wave flume geometry. The approach takes into account small amplitude seiching in a 1D horizontal canal of depth $\mathrm{h}(x)$. The governing equations are given by the linear long wave equations, as follows:

$$
\begin{gathered}
\eta_{t}+(z u)_{x}=0 \\
u_{t}+g \eta_{x}=0
\end{gathered}
$$

where $\eta$ is water surface displacement, $u$ is horizontal velocity, and $t$ is the time. The seiching spans the interval $0 \leq x \leq L$. The boundary condition at a wall boundary is taken to be

$$
q=u=\eta_{x}=0 ; x=0
$$

therefore implying an impermeability condition.

At $x=L$, the motion remains bounded by the sloping beach.

The elimination of $u$ is obtained by imposing:

$$
\eta_{t}-g\left(z \eta_{x}\right)_{x}=0 ; 0 \leq x \leq L
$$

In the case of time-harmonic motion with angular frequency $\omega$, considering $\lambda=\omega^{2} / g$ as the eigenvalue for the problem, Equation (5) can be rewritten as

$$
g\left(z \eta_{x}\right)_{x}+\lambda \eta=0
$$

Due to the sloping shoreline boundary condition, Equation (6) does not represent a standard Sturm-Liouville problem. The required Liouville transformation leads to the choice of the volume flux, $q=z u$, as a dependent variable, giving the following equation:

$$
q_{\mathrm{xx}}-\lambda z^{-1} q=0
$$

Equation (7) is finite differenced using centered second-order derivatives. In order to solve the resulting matrix eigenvalue problem, the EIG routine in MATLAB ${ }^{\mathrm{TM}}$ software is applied. Equations (8) and (9) provide the corresponding expansion, orthogonality condition, and dispersion relation, respectively:

$$
\begin{gathered}
q(x)=\sum_{n=1}^{\infty} q_{n} F_{n}(x) \\
\int_{0}^{L} z^{-1} F_{n} F_{m} \mathrm{~d} x=0 ; n \neq m \\
\omega_{n}^{2}=-g \frac{\int_{0}^{L}\left(F_{n}^{\prime}\right)^{2} \mathrm{~d} x}{\int_{0}^{L} z^{-1} F_{n}^{2} \mathrm{~d} x}
\end{gathered}
$$

where $F_{n}$ and $F_{m}$ represent the family of eigenmodes of order $n$ and $m$, respectively.

In the present study, the four families of eigenmodes, $F_{1}, F_{2}, F_{3}$ and $F_{4}$, have been determined by solving numerically Equations (8)-(10).

As demonstrated by Kirby et al. [45], the method is reliable also in the case of nonlinearity. In fact, the modal amplitude evolution addressed to linear and nonlinear interactions, measured during the large scale experiment at the Hinsdale Wave Research Laboratory [46], occurred on similar timescales. Such experiments took place in a wave flume with overall dimension and sand characteristics very 
similar to those of SUSCO experiments. In fact, the wave flume was $104 \mathrm{~m}$ long, $3.7 \mathrm{~m}$ wide and $4.6 \mathrm{~m}$ deep. This helps support the validity of results discussed in the following.

\subsection{Runup Estimation}

The runup tagging process began from camera calibration phases, by determining the relative position of a minimum of four reference points in the frame. In this study, eight reference points have been considered, in order to define the relative location and orientation of the camera. Target points were the tips of the optical backscatter sensors and the microacoustic wave gauges, the positions of which are known and remain stationary during machining. Once defined in the frame, the coordinates of the frame of reference points, an Image Processing Toolbox ${ }^{\mathrm{TM}}$ in MATLAB ${ }^{\mathrm{TM}}$ is used to define the relative position of all remaining pixels in the frame (Figure 3), as described by [47-50]. A particular optical filter of the images was applied in order to bring out the visual differences between dry and wet zones. Then, the relative position of runup along the same cross shore section (the centerline of wave flume) was determined as separation between dry and wet zones.

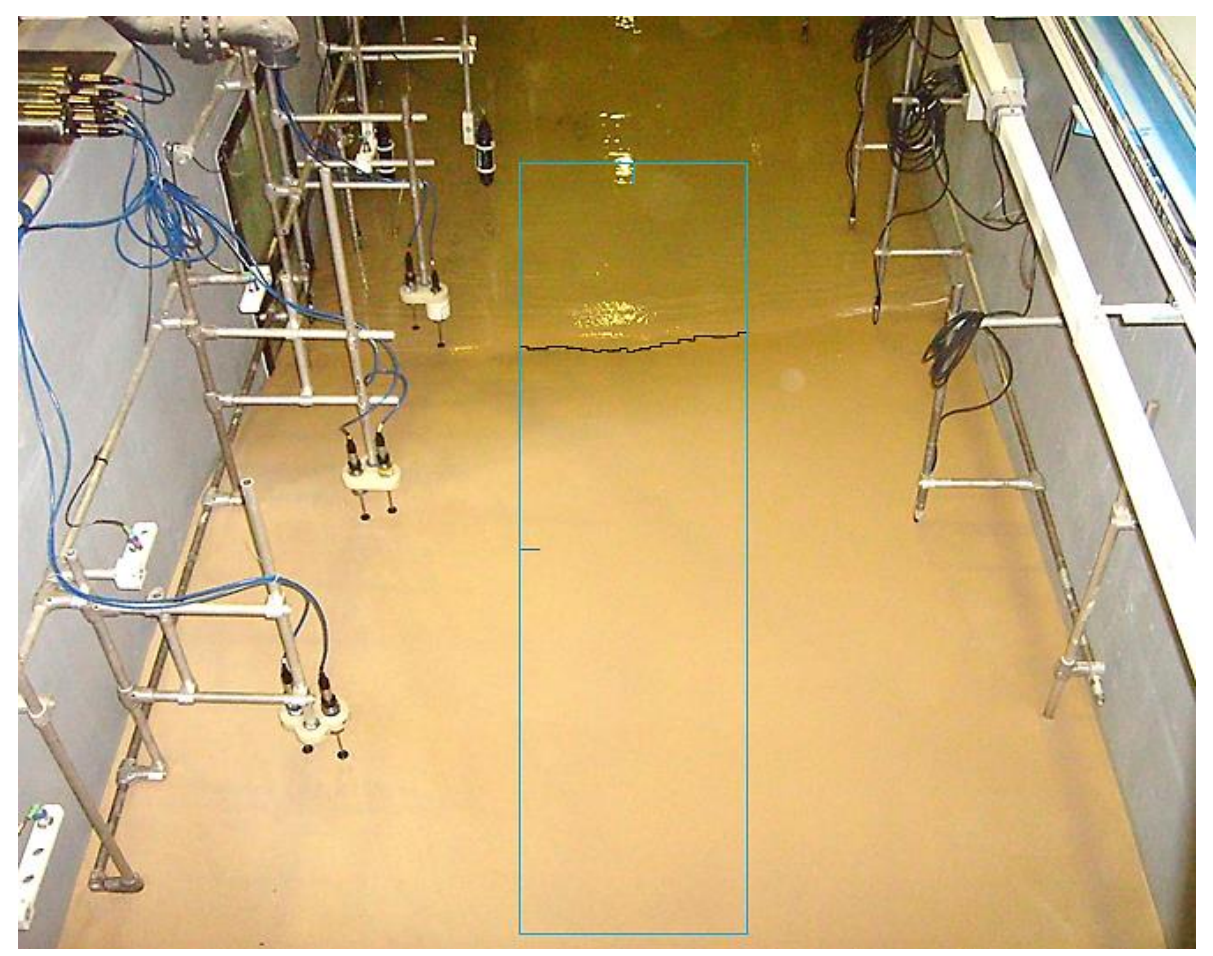

Figure 3. Image of the wave flume after geometric rectification.

The analyzed videos focused on the first three minutes of each step. Therefore, the computed runup measurements are not significantly affected by morphodynamic changes, since each test starts from the same underlying beach conditions. The good agreement between runup values derived from video analysis and the ones derived on some uprush/backwash cycle extrapolating the measurements from micro-acoustic wave gauges (that only provide the height of the swash lens), provides confidence in the technique.

\section{Results}

\subsection{Harmonics}

Spectral power density related to the wage gauge WG5 at $21.58 \mathrm{~m}$ in the wave flume is presented in Figure $4 a$,f. 

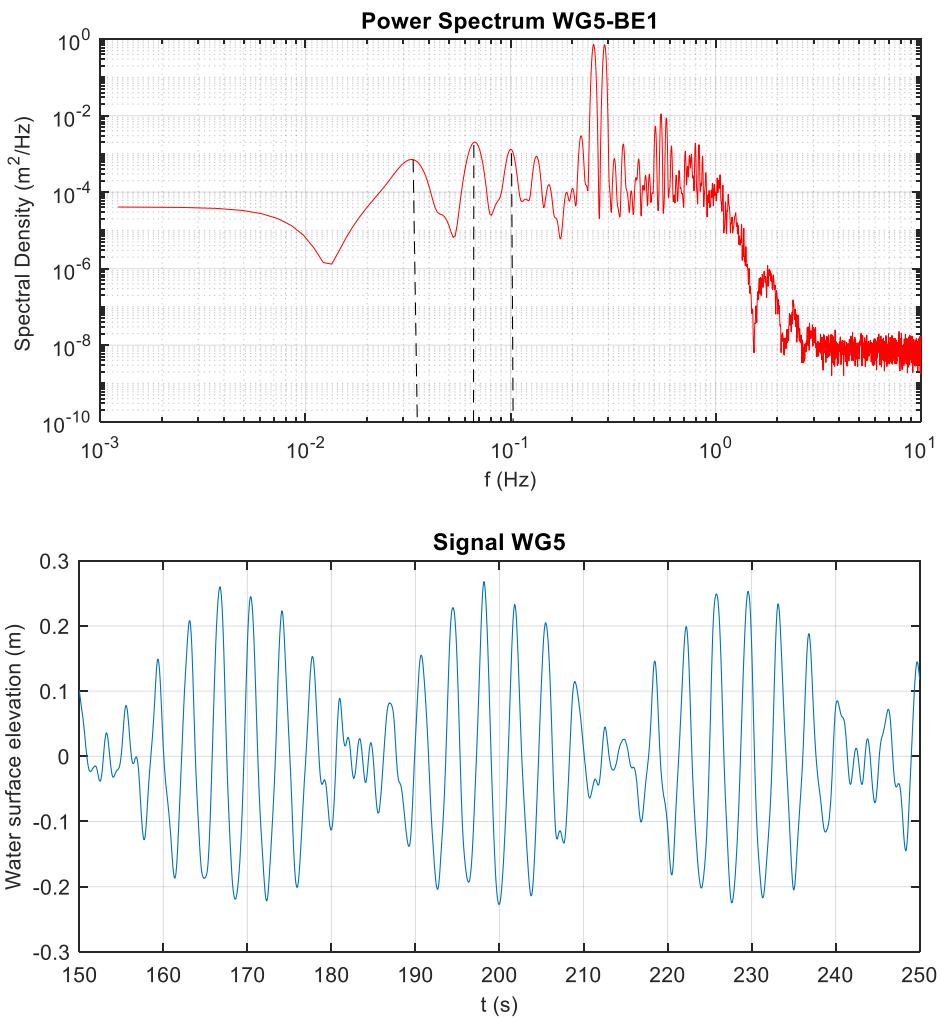

(a)
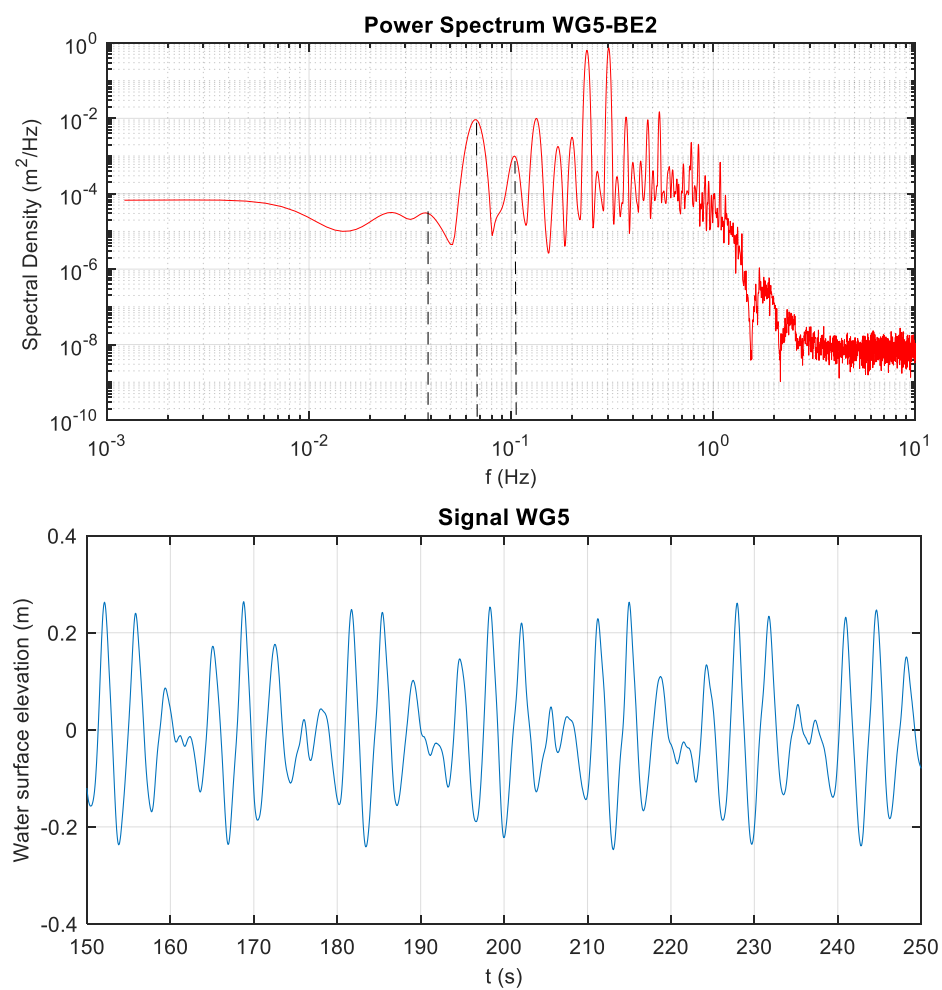

(b)

Figure 4. Cont. 

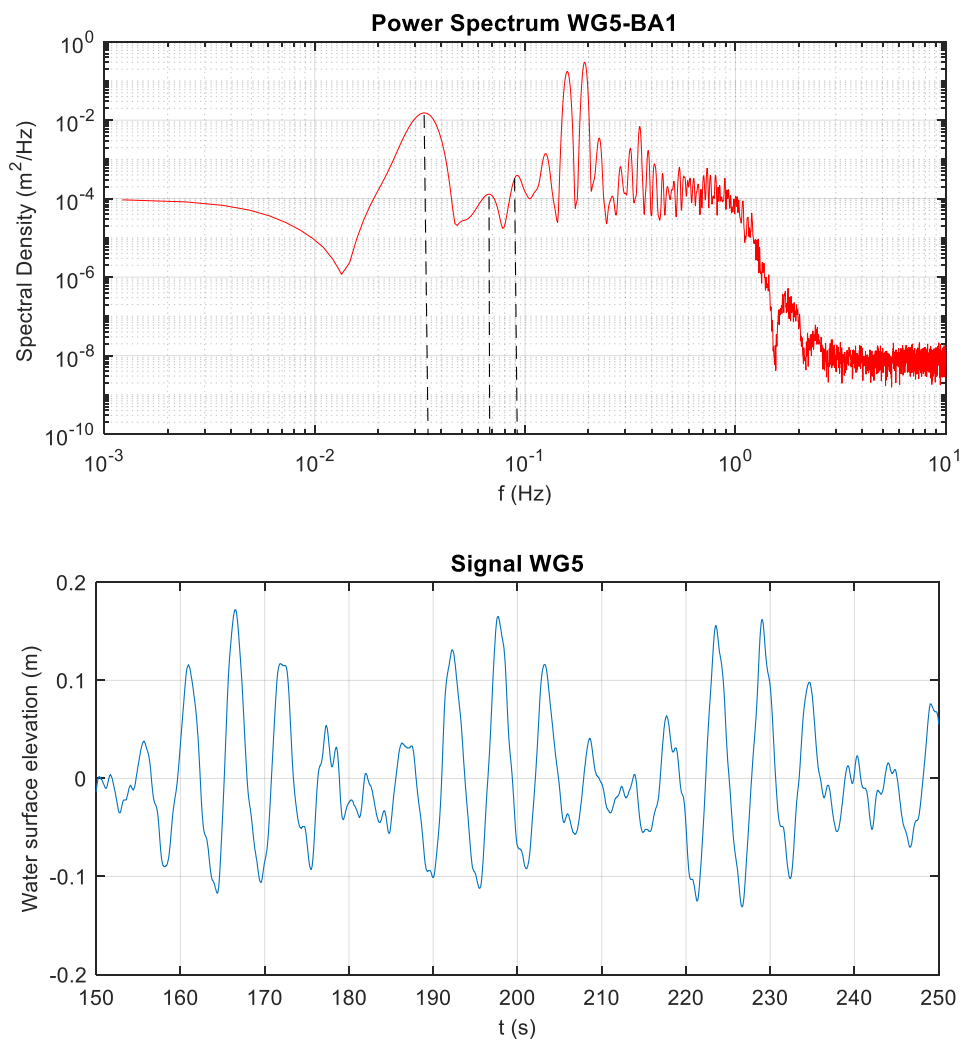

(c)
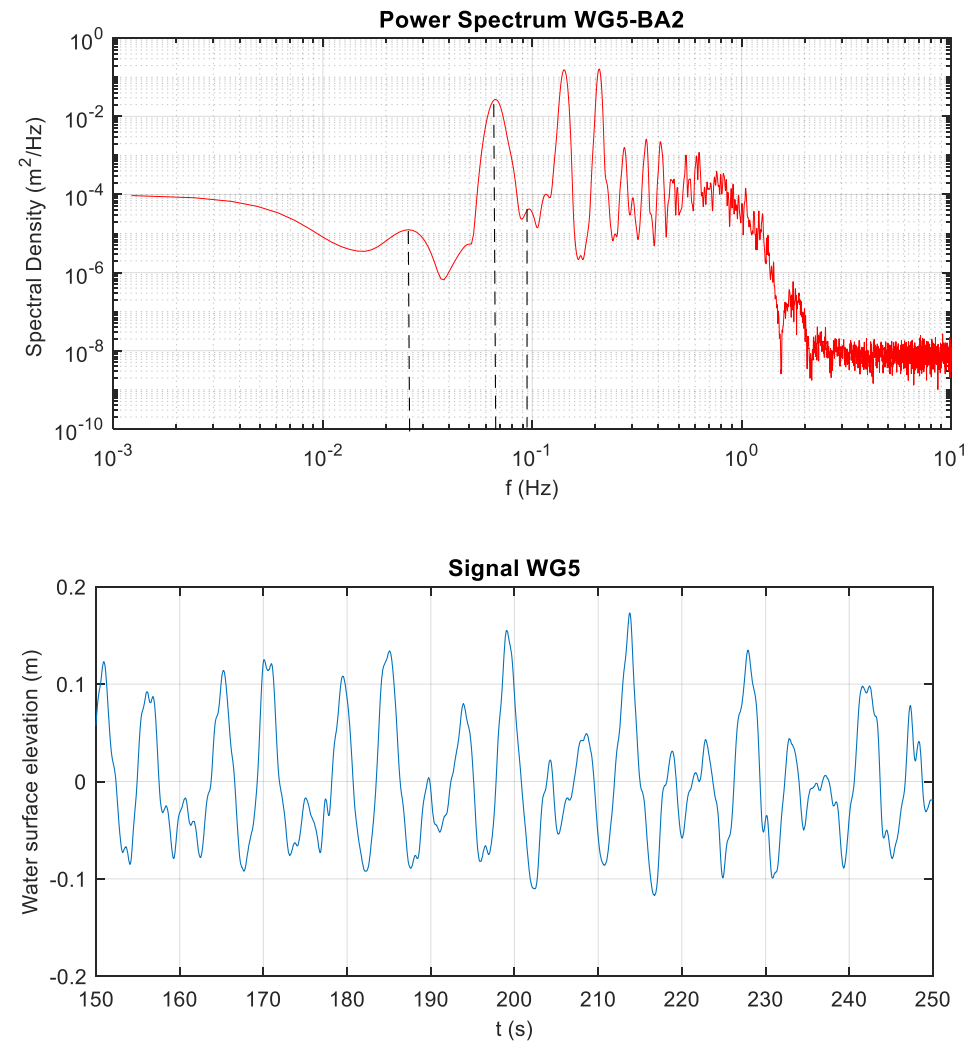

(d)

Figure 4. Cont. 

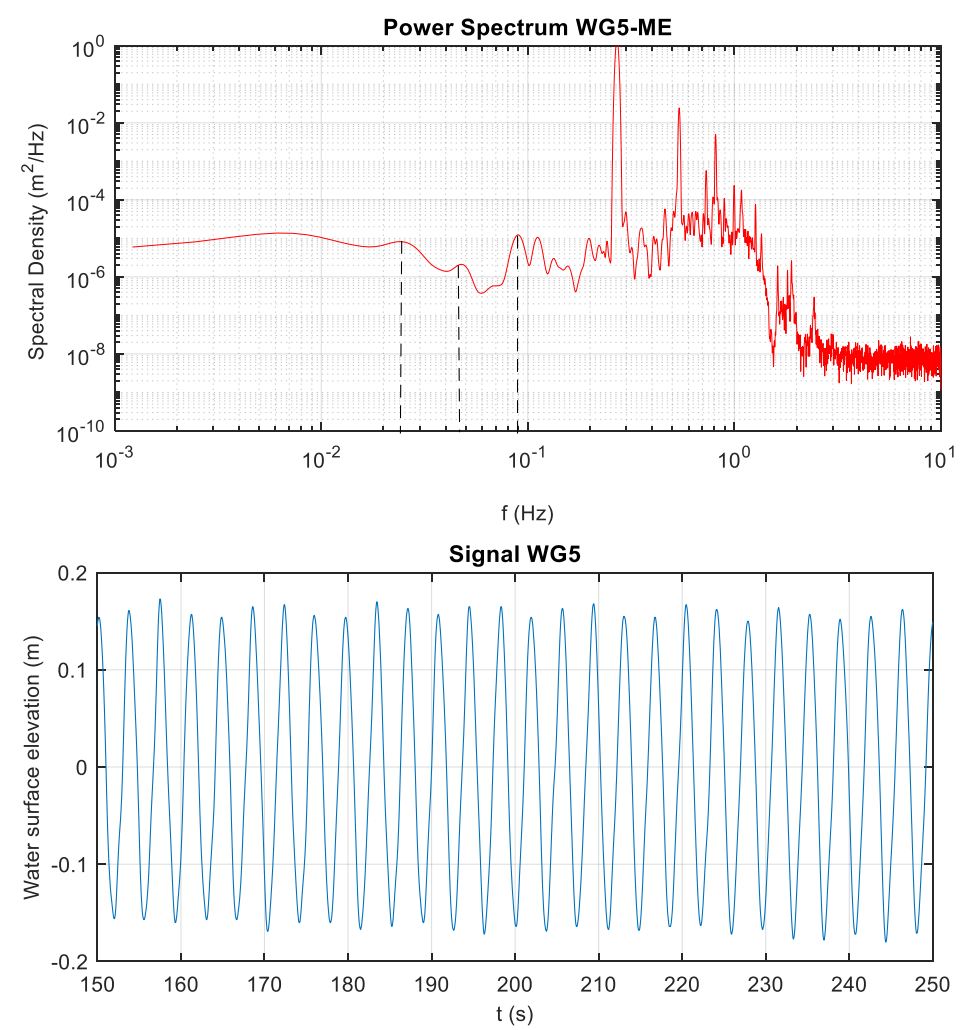

(e)
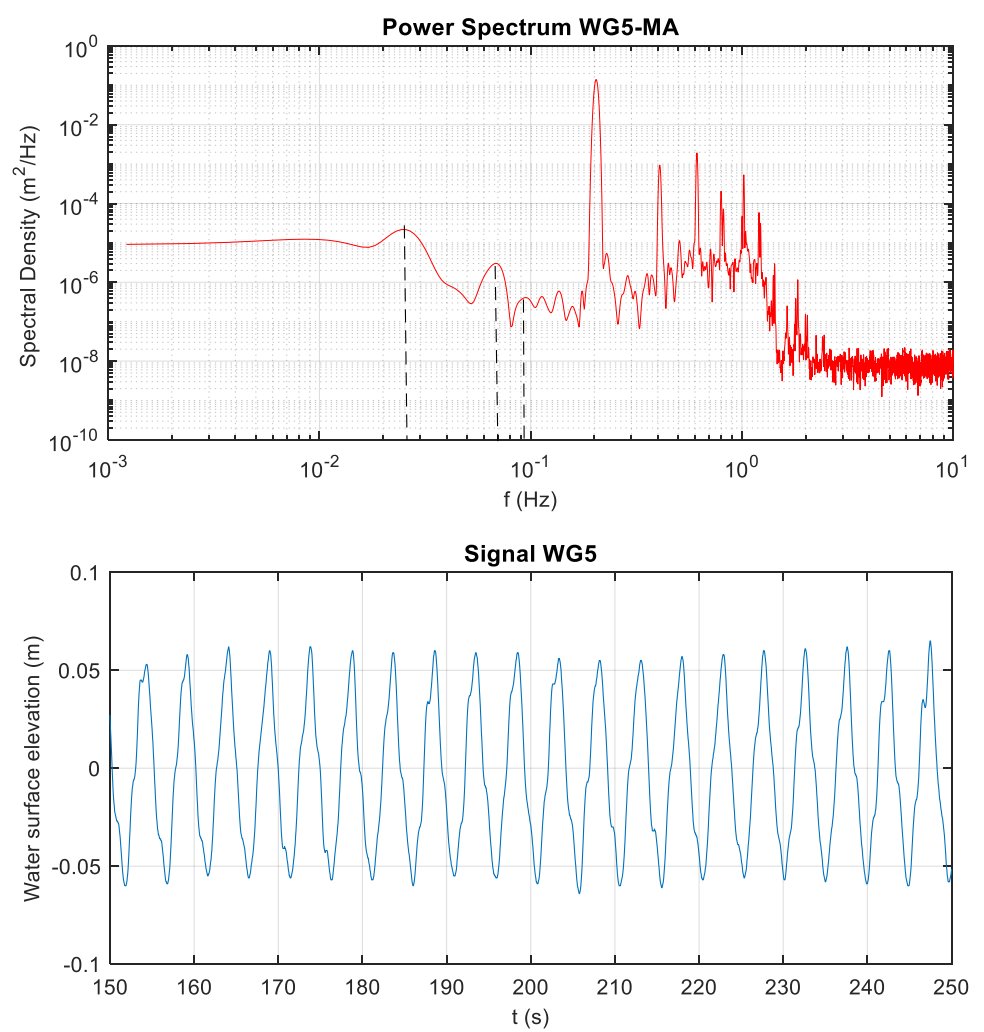

(f)

Figure 4. Power spectral density and time series water surface elevation for test: (a) BE_1; (b) BE_2; (c) BA_1; (d) BA_2; (e) ME; and (f) MA. Dashed black lines show the peaks in the low frequencies range used in the present analysis. 
In Tables 3-5, the power spectral density peak values for the first, second and third harmonic and the corresponding frequencies and periods are defined.

Table 3. Peak frequencies, periods and power spectral density for BE_1 and BE_2 tests.

\begin{tabular}{ccccc}
\hline & & $\mathbf{f ~ ( H z )}$ & $\mathbf{T}(\mathbf{s})$ & $\mathbf{E}\left(\mathbf{m}^{2} / \mathbf{H z}\right)$ \\
\hline \multirow{2}{*}{ Test BE_1 } & 1st harmonic & 0.033 & 30.3 & $7.02 \times 10^{-4}$ \\
& 2nd harmonic & 0.051 & 19.5 & $7.67 \times 10^{-6}$ \\
& 3rd harmonic & 0.067 & 14.9 & $2.11 \times 10^{-3}$ \\
\hline & & $\mathbf{f ~ ( H z )}$ & $\mathbf{T}(\mathbf{s})$ & $\mathbf{E}\left(\mathbf{m}^{\mathbf{2}} / \mathbf{H z}\right)$ \\
\hline \multirow{2}{*}{ Test BE_2 } & 1st harmonic & 0.035 & 28.2 & $3.66 \times 10^{-5}$ \\
& 2nd harmonic & 0.067 & 14.9 & $9.73 \times 10^{-3}$ \\
& 3rd harmonic & 0.103 & 9.6 & $7.14 \times 10^{-4}$ \\
\hline
\end{tabular}

Table 4. Peak frequencies, periods and power spectral density for BA_1 and BA_2 tests.

\begin{tabular}{|c|c|c|c|c|}
\hline & & $\mathrm{f}(\mathrm{Hz})$ & $\mathrm{T}(\mathrm{s})$ & $\mathrm{E}\left(\mathrm{m}^{2} / \mathrm{Hz}\right)$ \\
\hline \multirow{4}{*}{ Test BA_1 } & 1st harmonic & 0.033 & 30.3 & $1.53 \times 10^{-2}$ \\
\hline & 2nd harmonic & 0.067 & 14.9 & $6.00 \times 10^{-5}$ \\
\hline & 3rd harmonic & 0.092 & 10.8 & $4.99 \times 10^{-4}$ \\
\hline & & $\mathrm{f}(\mathrm{Hz})$ & $\mathrm{T}(\mathrm{s})$ & $\mathrm{E}\left(\mathrm{m}^{2} / \mathrm{Hz}\right)$ \\
\hline \multirow{3}{*}{ Test BA_2 } & 1st harmonic & 0.029 & 34.1 & $5.54 \times 10^{-6}$ \\
\hline & 2nd harmonic & 0.067 & 14.9 & $2.88 \times 10^{-2}$ \\
\hline & 3rd harmonic & 0.116 & 8.6 & $7.22 \times 10^{-5}$ \\
\hline
\end{tabular}

Table 5. Peak frequencies, periods and power spectral density for monochromatic tests under erosive (ME) and accretive (MA) conditions.

\begin{tabular}{|c|c|c|c|c|}
\hline & & $\mathrm{f}(\mathrm{Hz})$ & $\mathrm{T}(\mathrm{s})$ & $\mathrm{E}\left(\mathrm{m}^{2} / \mathrm{Hz}\right)$ \\
\hline \multirow{4}{*}{ Test ME } & 1st harmonic & 0.024 & 41.7 & $8.22 \times 10^{-6}$ \\
\hline & 2nd harmonic & 0.049 & 20.5 & $2.72 \times 10^{-6}$ \\
\hline & 3rd harmonic & 0.089 & 11.2 & $8.23 \times 10^{-6}$ \\
\hline & & $\mathrm{f}(\mathrm{Hz})$ & $\mathrm{T}(\mathrm{s})$ & $\mathrm{E}\left(\mathrm{m}^{2} / \mathrm{Hz}\right)$ \\
\hline \multirow{3}{*}{ Test MA } & 1st harmonic & 0.023 & 45.5 & $1.13 \times 10^{-5}$ \\
\hline & 2nd harmonic & 0.055 & 18.2 & $6.49 \times 10^{-7}$ \\
\hline & 3rd harmonic & 0.072 & 13.9 & $1.55 \times 10^{-7}$ \\
\hline
\end{tabular}

In the case of erosive conditions, bichromatic waves with narrower bandwidth (BE_2) give a lower peak associated with the 1st harmonic than the case with a larger bandwidth (BE_1). Such a trend is confirmed in the bichromatic accretive condition (BA_1), being the 1st harmonic 12\% higher than that related to the bichromatic waves with larger bandwidth (BA_2).

In terms of energy around the harmonics, the following considerations can be made:

- Passing from the first to the third harmonic, a decrease and then an increase in power density was found (Tables 3 and 4) for the bichromatic waves with narrower bandwidth (BE_1 and BA_1).

- An opposite behavior can be observed for the bichromatic waves with larger bandwidth (BE_2 and BA_2), in which the power density of the second harmonic is the highest.

- Monochromatic waves in the erosive condition (ME) give higher peak frequency response at first, second and third harmonic than the accretive condition (MA).

- The energy level around the first harmonic for ME case is higher than the accretive case, as expected. However, at the second and third harmonics, the monochromatic erosive wave condition is associated with the lower power spectral density values (Table 5). 
In Table 6, the total power spectral density and various sections of the spectra related to the bichromatic and monochromatic tests are given. Generally, it is noted that most of the energy is in the higher part of the spectra, after $0.1 \mathrm{~Hz}$, for bichromatic and monochromatic waves. In particular, the bichromatic waves with narrower bandwidth for both studied conditions, erosive and accretive (BE_1 and BA_1), yield higher total energy and at the section with frequencies minor of $0.03 \mathrm{~Hz}$ than the waves with larger bandwidth. On the contrary, such behavior is not confirmed in the spectra section $<0.1 \mathrm{~Hz}$; in fact, the amount of power spectral density is lower by $66 \%$ and $47 \%$ for BE_1 and BA_1 cases, respectively, than the BE_2 and BA_2 cases.

Table 6. Power spectral density for various sections of the spectra for the bichromatic and monochromatic tests.

\begin{tabular}{ccccccc}
\hline $\mathbf{E}\left(\mathbf{m}^{\mathbf{2}} \mathbf{\text { Hz}}\right)$ & BE_1 & BE_2 & BA_1 & BA_2 & ME & MA \\
\hline total & $1.19 \times 10$ & $1.15 \times 10$ & 4.25 & 3.00 & $1.13 \times 10$ & 1.13 \\
$<0.1 \mathrm{~Hz}$ & $2.70 \times 10^{-2}$ & $7.90 \times 10^{-2}$ & $1.26 \times 10^{-1}$ & $2.40 \times 10^{-1}$ & $2.11 \times 10^{-4}$ & $2.49 \times 10^{-4}$ \\
$<0.03 \mathrm{~Hz}$ & $1.70 \times 10^{-3}$ & $6.39 \times 10^{-4}$ & $2.13 \times 10^{-2}$ & $2.16 \times 10^{-4}$ & $6.77 \times 10^{-5}$ & $2.15 \times 10^{-4}$ \\
\hline
\end{tabular}

Moreover, for monochromatic waves in the erosive condition, the total energy is higher with respect to the accretive condition. An opposite behaviour is shown for spectra with the frequency of $0.1 \mathrm{~Hz}$ and $0.03 \mathrm{~Hz}$, as observed in Table 6. As confirmed in Figure 4 and Table 5, most of the energy is moved in the higher part of the spectra.

Further considerations can be observed in Figure 5, in which the ratio between spectral density level at different harmonics is shown. In particular, it is noted:

- a higher ratio between the spectral density of the second and first harmonic for bichromatic waves with larger bandwidth than that related to the waves with narrower bandwidth, in both conditions erosive and accretive.

- $\quad$ BE_1 and BA_1 cases highlight higher ratio values between the third and second harmonic due to the narrower bandwidth that characterizes the wave conditions.

- the ratios calculated between spectral density of the 2 nd/1st and 3rd/2nd harmonic for monochromatic waves are similar. Therefore, the behavior of the bichromatic waves and the influence of the three harmonics could be addressed to the nonlinear interactions due to wave bandwidth.

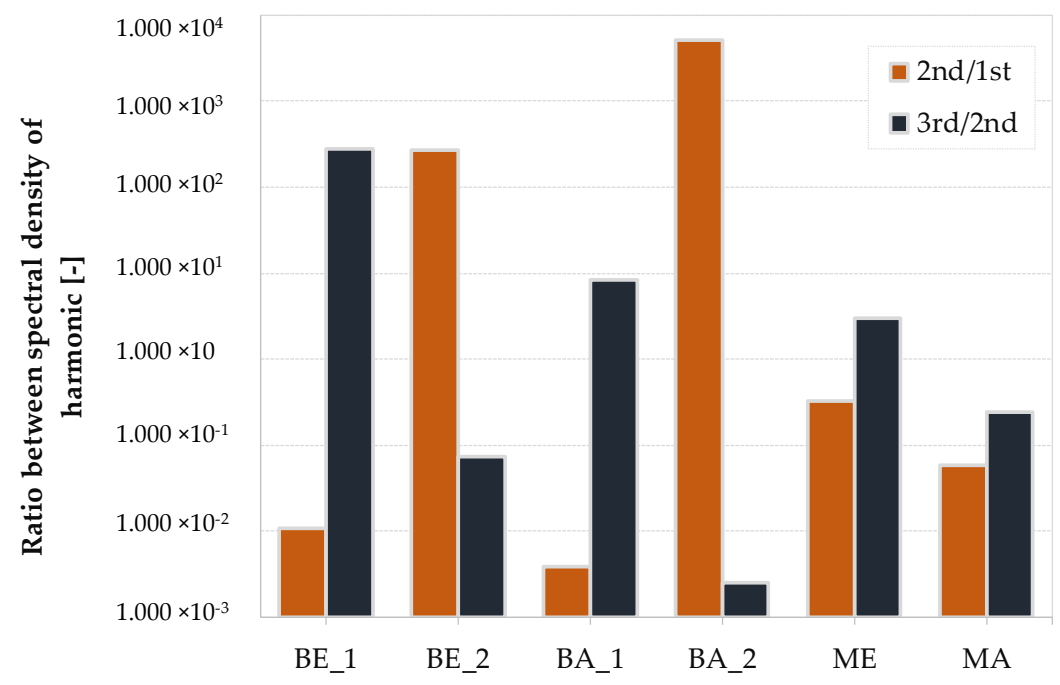

Figure 5. Ratio between spectral density level at different harmonics of the bichromatic and monochromatic tests. 


\subsection{Eigenvalues}

In order to analyze the longest standing waves in the flume, the lowest frequencies are determined and compared with those measured. The wave flume natural frequencies are provided by carrying out the eigenvalue analysis, as in details described by Riefolo et al. [51,52], where different formulas found in the literature were compared. Here, the frequencies calculated with the formula proposed by Merian [43], by referring to the maximum water depth $(2.5 \mathrm{~m})$ in the wave flume, are shown in Table 7. The discrepancy between measured and calculated first, second and third modes is graphically represented in Figure 6. For BE_1, ME and MA cases, a good correspondence has been found, for which the influence of wave flume-generated seiching can be definitively upheld. On the other hand, the bichromatic waves with larger bandwidth for both erosive (BE_2) and accretive (BA_2) conditions give different variations from the perfect fit line (grey dot-dashed line), especially at the second and third harmonic.

Table 7. Eigenvalues calculated for the wave flume through the formula proposed by Merian [43].

\begin{tabular}{cc}
\hline Mode & $\mathbf{f}(\mathbf{H z})$ \\
\hline 1st & 0.0248 \\
2nd & 0.0495 \\
3rd & 0.0742 \\
\hline
\end{tabular}

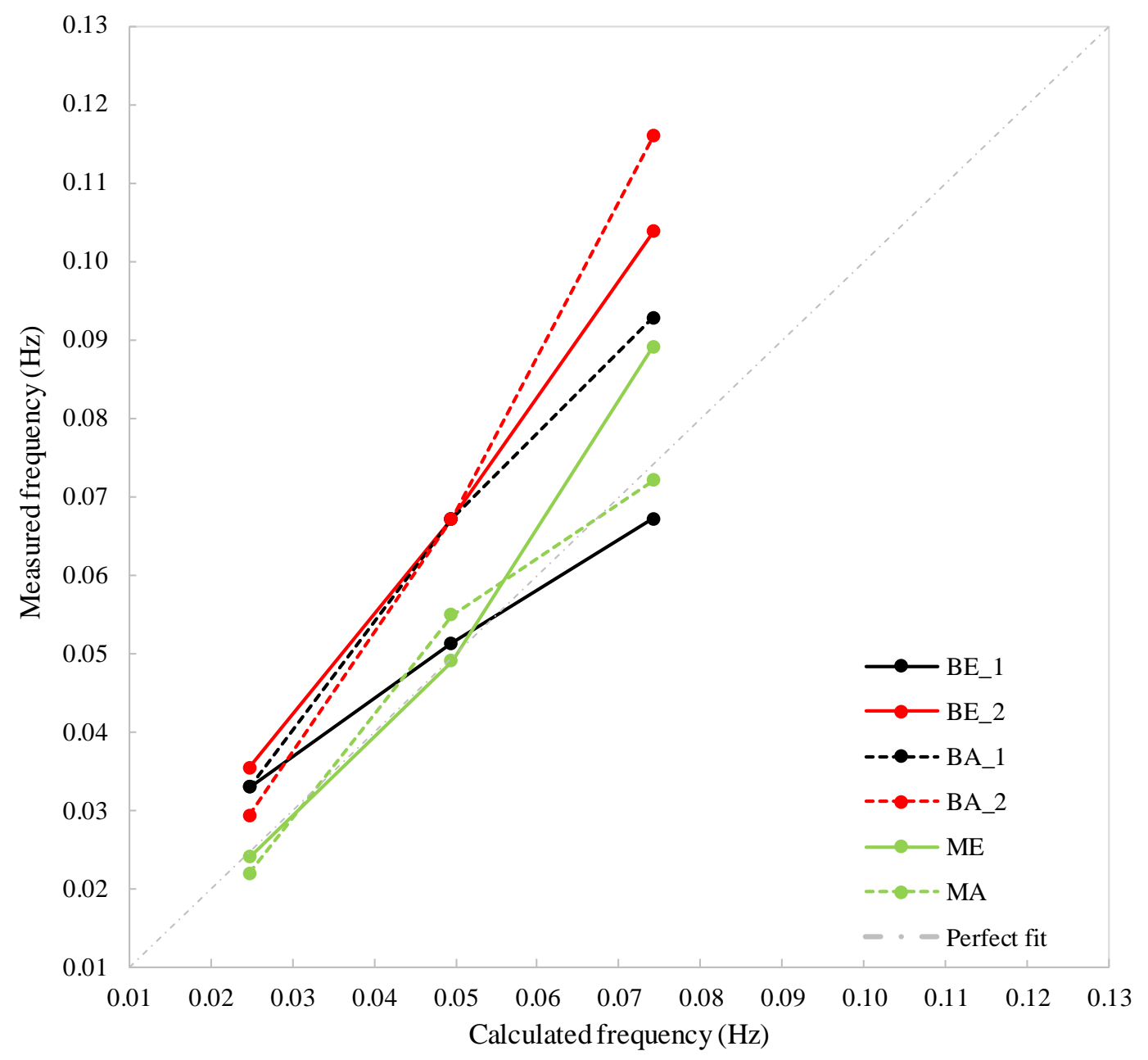

Figure 6. Frequencies plot of measured versus calculated first, second and third eigenmodes. 


\subsection{Measured Runup}

Maximum runup measurements took place within the first three minutes of each first step, as aforementioned. This approach is applied in order to identify the role of spectral wave components and bandwidth on runup, starting from the same underlying beach conditions. No clear relationship is recognized between runup and spectral wave components. However, some points are evident as demonstrated in Table 8, in fact:

- despite comparable energy levels, erosive monochromatic waves give a runup that is four times lower than runup for the test BE_2.

- Enlarging the bandwidth (which corresponds to a reduction of the wave grouping), the highest runup values are observed for both erosive and accretive conditions.

- Tests BE_2 and BA_2 give a runup about two times higher than test BE_1 and BA_1, respectively.

Table 8. Maximum runup measured within the first three min of each step for bichromatic and monochromatic tests.

\begin{tabular}{cccc}
\hline Test & Measured $(\mathbf{m})$ & Test & Measured $(\mathrm{m})$ \\
\hline MA & 0.059 & ME & 0.11 \\
BA_1 & 0.242 & BE_1 & 0.17 \\
BA_2 & 0.368 & BE_2 & 0.42 \\
\hline
\end{tabular}

Hence, it appears as the role of spectral wave components is related to the interaction between successive swash events (swash-swash interaction) and the interaction between standing waves and incident bores on runup.

\section{Additional Considerations}

The mode frequencies determined through the eigen analysis-based on water depth $z$ of the wave flume-can represent a powerful tool to highlight the effects of the LFWs and merit further consideration.

- In fact, through the computation of the four lowest modes $\left(\mathrm{F}_{1}-\mathrm{F}_{4}\right)$ for volume flux in the wave flume (plotted in Figures 7 and 8), interesting results can be achieved. A nonlinear pattern of the modes $\mathrm{F}_{1}-\mathrm{F}_{4}$ is identified near the breaking zone for all studied tests. It is noted that the results corresponding to the bichromatic waves are characterized by nonlinear effects, especially near the breaking point where free long waves are generated $[8,9]$. Therefore, this finding is in accordance with Longuet-Higgins and Stewart $[53,54]$ since the bichromatic wave groups force an associated bound long wave at the group frequency.

- An opposite behavior of volume flux eigenmodes is shown for the fourth mode $\mathrm{F}_{4}$ of the BE_1 and BE_2 cases (Figure 7a,b). Furthermore, for the first and second mode, a dependency of the different bandwidths for bichromatic waves in accretive conditions is observed (Figure 7c,d).

- The eigenmodes for volume flux, $q$, related to the profile measured in the monochromatic tests show a different variation probably due to the nonlinearity effects for the first and second modes in both erosive and accretive conditions.

- The harmonic disturbance for bichromatic waves with narrower and larger bandwidth could lead to erosion phenomena where the formation of well visible bars is seen. The resulting profiles and net sediment transport were consistent with these initial estimates [34]. 


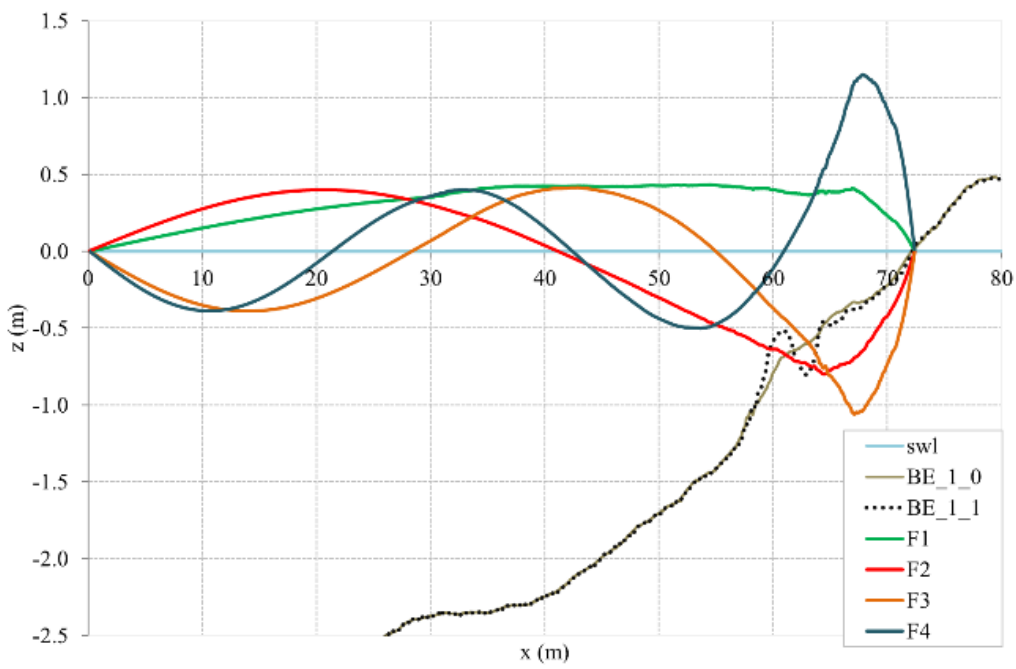

(a)

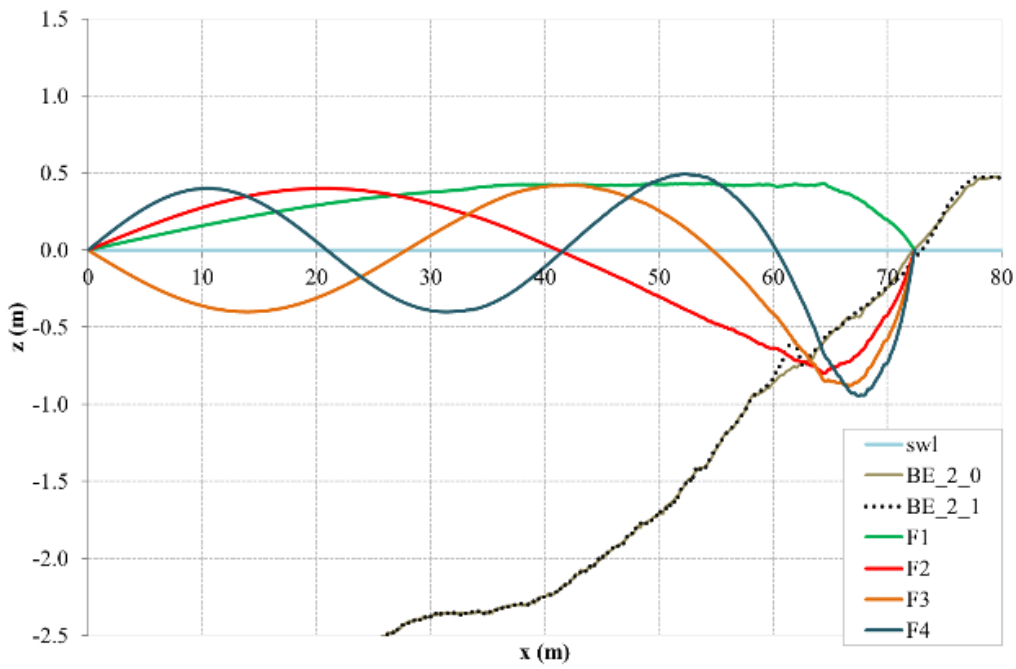

(b)

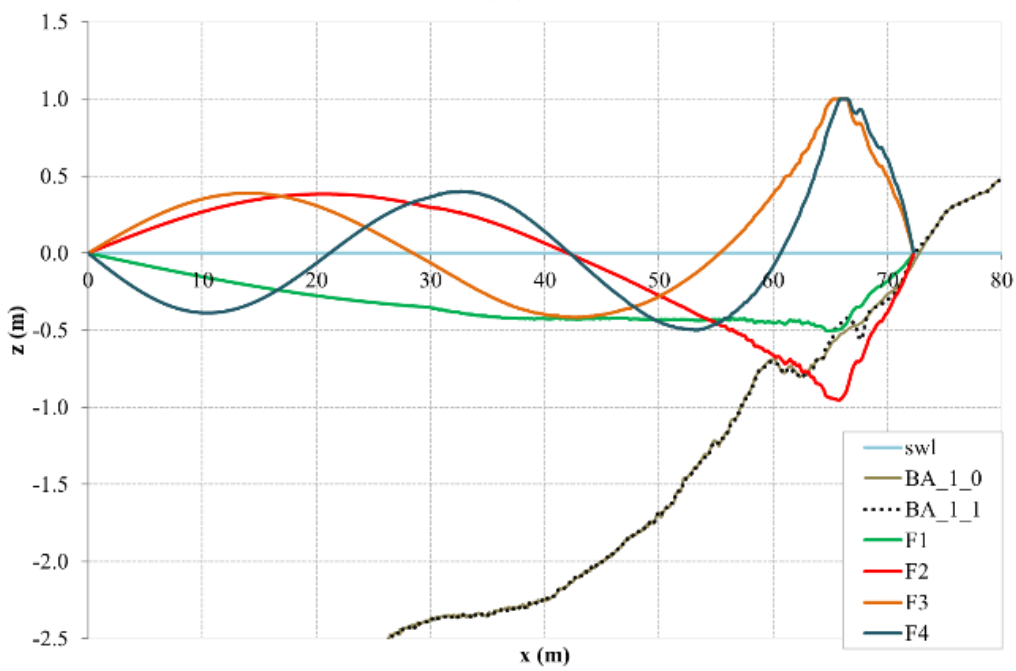

(c)

Figure 7. Cont. 


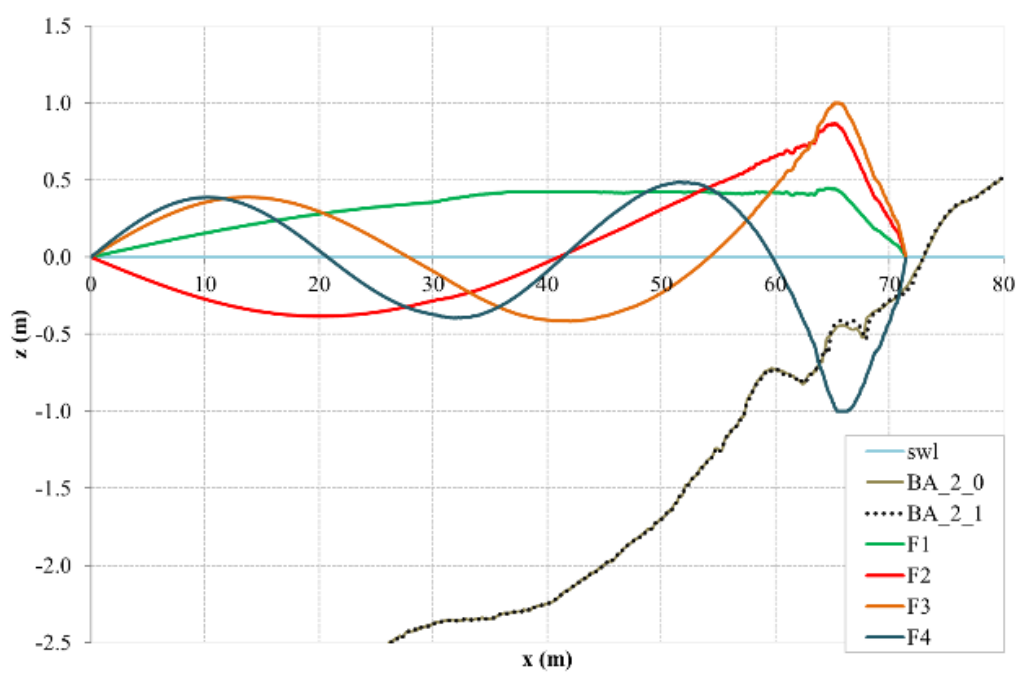

(d)

Figure 7. Eigenmodes for volume flux $q$ related to the profile measured in bichromatic tests: (a) BE_1; (b) BE_2; (c) BA_1 and (d) BA_2.

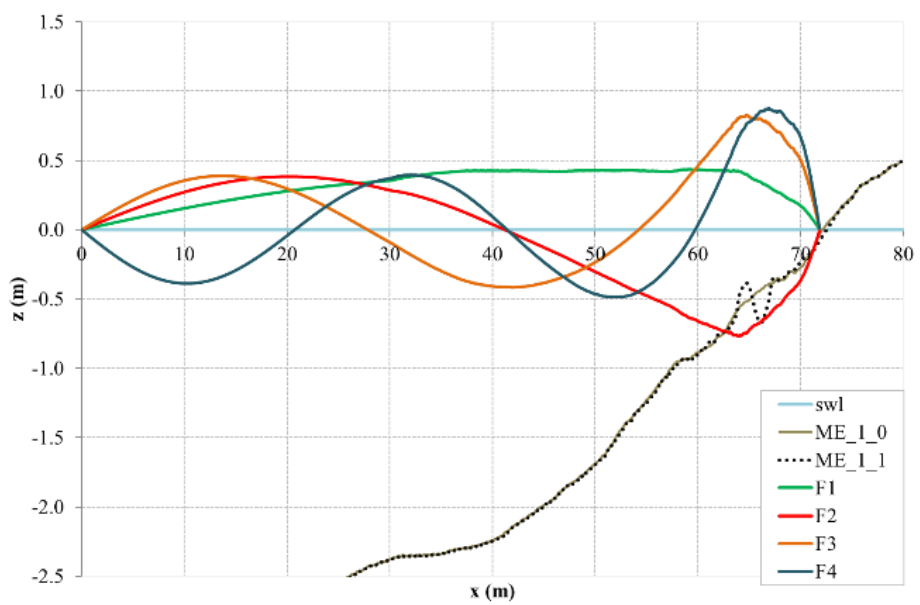

(a)

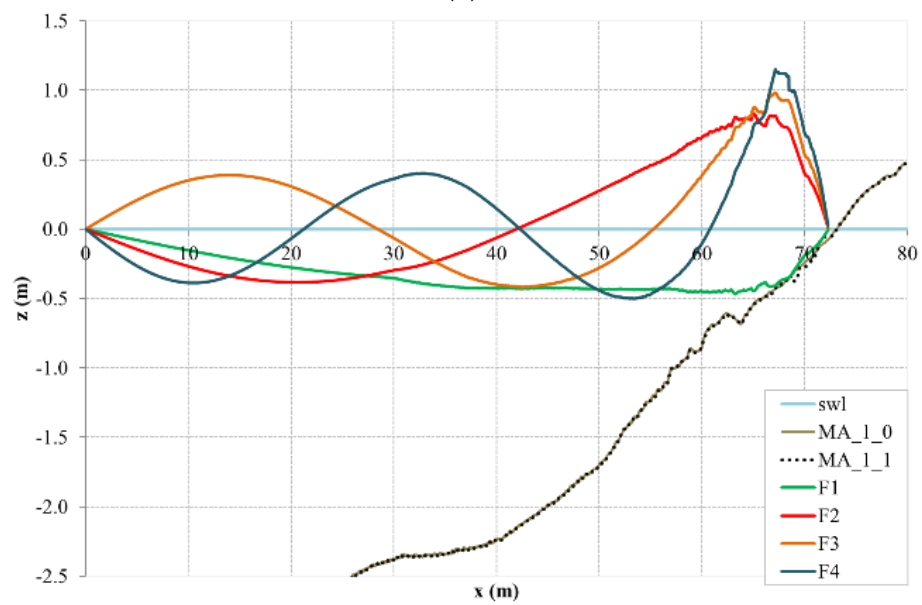

(b)

Figure 8. Eigenmodes for volume flux $q$ related to the profile measured in monochromatic tests: (a) ME and (b) MA. 
Moreover, it is worth noting that the local effect on a beach profile of bichromatic or monochromatic waves can be significantly different due to the interaction of the LFWs that affects the spectra. Considering the typical pattern of modes $\mathrm{F}_{1}-\mathrm{F}_{4}$ (according to [45,52]), some differences can be observed in Figure 8. In fact, it is identified:

- $\quad$ an accretive pattern in the case of bichromatic waves BE_1 for the fourth mode F4;

- $\quad$ an erosive behavior for the second mode in BA_1;

- $\quad$ an erosive structure for the first and fourth mode in case BA_2;

- $\quad$ an accretive pattern for the F3 and F4 in ME;

- a completely erosive pattern for MA case.

Influence on Swash Zone Sediment Transport

In the swash zone (SZ), the dissipation of short-wave (wind and swell) energy occurs, while the LFW energy is generally reflected back seaward. Moreover, intense short-short and short-long wave interactions at the surf-swash boundary can influence the generation and reflection of further LFWs $[55,56]$. Superficial SZ hydrodynamics, subsurface SZ hydrodynamics, sediment dynamics and co-related beachface morphodynamics are strongly determined by the swash motion's frequency in non-tidal regimes [57-61]. Therefore, for low frequency motions and sediment transport, important feedback can be found, according to Russell [62] and Smith and Mocke [63]. LFWs, in particular, lead to mobility of the sediment into suspension by the short waves.

Based on this reasoning, Figure 9 shows the net sediment volume variation in the $S Z$, and $\Delta V_{S Z}$, approximated as the emerged beach, between the start and end of the test is provided. Such a variation is determined by applying changes in bed elevation between profiles above the SWL.

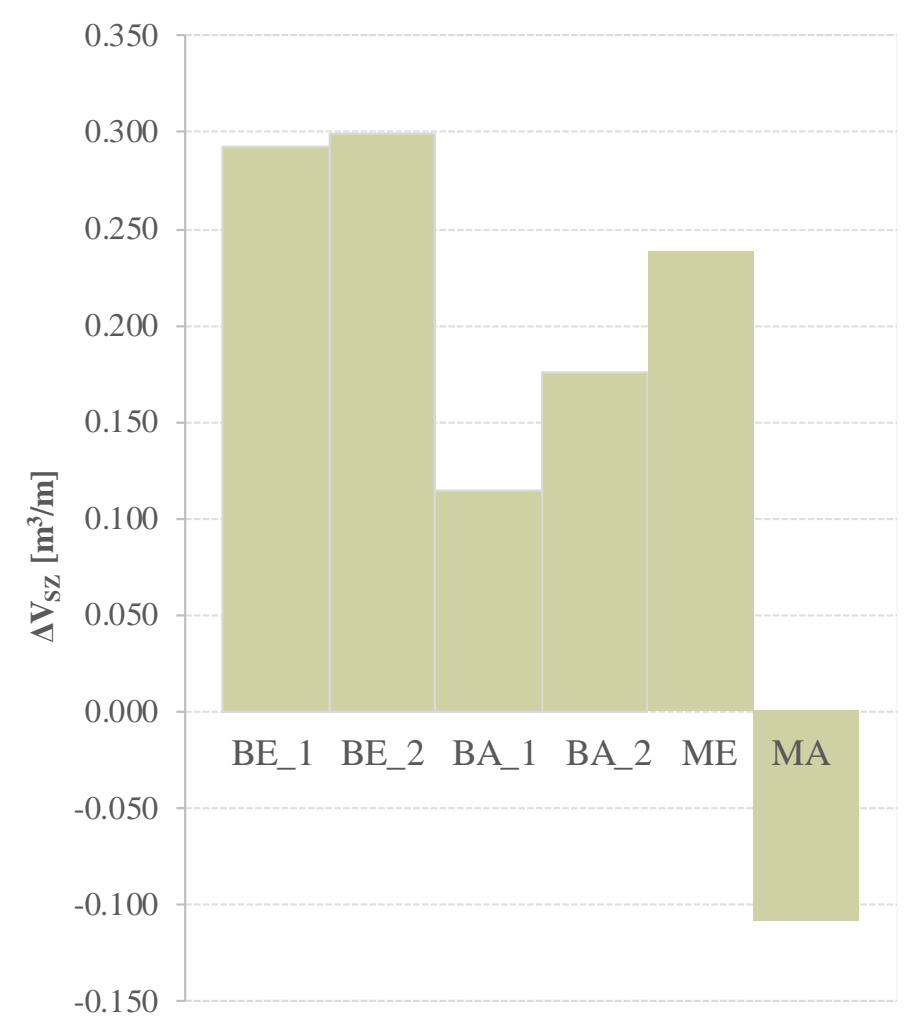

Figure 9. Net sand volume variation in the emerged swash zone (water depth $>0$ ) after 24 min of wave generation: positive values represent accretion or landward transport; negative values represent erosion or seaward transport, for bichromatic and monochromatic tests. 
It is observed that all wave conditions related to the first step of experiments lead to a landward net sediment transport, except for case MA. In particular, for bichromatic waves with narrower bandwidth, the power spectral density associated with the first harmonic has been found larger than the power level of the second mode, increasing the disturbance effect of the 1st harmonic itself. On the contrary, for the bichromatic waves with larger bandwidth, the power spectral density associated with the second harmonic is larger than the energy of the first mode, increasing the disturbance effect of the 2nd harmonic. Therefore, the different bandwidths of the bichromatic waves are found to be influenced by the low frequency motions.

Furthermore, the net sand volume variation in the emerged swash zone is greater in the erosive condition than the accretive condition for bichromatic waves. Consequently, a morphological effect is observed in which the different bandwidths could promote the presence of the low-frequency motions responsible for nonlinear interactions.

It is also noted that the net sand volume variation in the emerged swash zone is higher in the erosive cases than those determined in the accretive cases, showing positive values. This behavior is in line with the typical erosion pattern along the profile of the bichromatic and monochromatic waves under erosive conditions. In particular, this effect is produced by the initial profiles during the experimental campaign with the same initial conditions. Therefore, the beach variations associated with the erosive cases arise when the equilibrium profile is reached, and the mean beachface slope changes. Hence, at the beginning of the tests, erosion of sediment provides some local deposition with positive slope change. What is also important is the erosive pattern under accretive monochromatic conditions. Here, the effect of resonance could be more evident; therefore accretive wave conditions could provide sweetening of the swash zone slope, by behaving more in a slightly erosive pattern.

\section{Conclusions}

A data set from controlled large-scale experiments at UPC were specifically used to identify seiching from various wave regimes and their effects on spectral components. In particular, monochromatic and bichromatic wave groups with different bandwidths were analysed.

In order to discriminate low frequency components, an eigenvalue decomposition was carried out. Comparing measured and calculated eigenvalues, an appreciable correspondence for the first harmonic has been found for all the bichromatics tests. Consequently, a wave flume-generated signature of the first harmonic can be identified. Moreover, for the monochromatic and the erosive bichromatic wave conditions with narrower bandwidth, a good correlation for other harmonics was also detected.

Results suggested that the wider bandwidth had the higher ratios between the spectral density of the second and first harmonic and the lower ratios between spectral density of the 2nd/1st and 3rd/2nd. Specifically, in enlarging the bandwidth:

- the highest power spectral density peak downshifted toward the second harmonic;

- enlargement of the swash zone was promoted and the runup values (in comparable morphodynamic initial condition) increased significantly;

- moving from the same initial profile, the sediment transport rate and related swash zone morphological changes became more important.

The effect of resonance was highlighted by a volume flux eigenmode analysis. For all the studied tests, a pattern of energy exchange between modes has been determined. In particular, the results related to the completely erosive pattern of $\mathrm{F}_{1}-\mathrm{F}_{4}$ modes in the MA case and the accretive pattern for $\mathrm{F}_{3}-\mathrm{F}_{4}$ in the $\mathrm{ME}$ case and the fourth mode in BE_1 case were consistent with the computed volume variation in the emerged swash zone. Hence, it appeared that the seiching effect could influence the interaction between successive swash events (swash-swash interaction) and the interaction between standing waves and incident bores on runup. Such interaction may be constructive or destructive in hydro-morphodynamics terms. 
It is appropriate to point out that in the swash zone the magnitude of net sediment volume suggests that low frequency oscillations could have a significant influence only on generation/development of secondary bedforms.

Further work is required to better understand quantitative implications of seiching in laboratory experiments for sandy slope profiles. Particularly, in order to investigate the seiching response when an equilibrium profile is achieved, including the morphodynamic feedback is important and additional analyses should be attempted on the last steps of each test of the UPC dataset.

Author Contributions: P.C. performed the laboratory experiments; L.R. conceived the analysis tools; L.R., P.C and D.V. contributed to analysis of the data; L.R. and P.C. wrote the paper; D.V. revised the paper draft; L.R. updated the paper according to their review.

Funding: The experimental programme discussed in this work, was supported by the European Community's Sixth Framework Programme, through the grant to the budget of the Integrated Infrastructure Initiative HYDRALAB III within the Transnational Access Activities, Contract No. 022441.

Acknowledgments: Special thanks go to James Kirby (University of Delaware) and Iván Cáceres (Universitat Politècnica de Catalunya) for their help in supporting data analysis.

Conflicts of Interest: The authors declare no conflict of interest.

\section{References}

1. Hasselmann, K.; Barnett, T.; Bouws, E.; Carlson, H.; Cartwright, D.; Enke, K.; Ewing, J.; Gienapp, H.; Hasselmann, D.; Kruseman, P. Measurements of Wind-Wave Growth and Swell Decay during the Joint North Sea Wave Project (JONSWAP); Deutches Hydrographisches Institut: Hamburg, Germany, 1973.

2. Pierson, W.J., Jr.; Moskowitz, L. A Proposed Spectral Form for Fully Developed Wind Seas Based on the Similarity Theory of SA Kitaigorodskii; DTIC Document: Fort Belvoir, VA, USA, 1963.

3. Hasselmann, K. On the nonlinear energy transfer in a gravity wave spectrum, Part I. General theory. J. Fluid Mech. 1962, 12, 481-500. [CrossRef]

4. Goda, Y. Irregular wave deformation in the surf zone. Coast. Eng. Jpn. 1975, 18, 13-26. [CrossRef]

5. Baldock, T.E.; O'Hare, T.J. Energy transfer and dissipation during surf beat conditions. In Proceedings of the 29th International Conference on. Coastal Engineering, Lisbon, Portugal, 19-24 September 2004; pp. 1212-1224.

6. Holman, R.A.; Bowen, A.J. Bar, bumps and holes: Models for the generation of complex beach topography. J. Geophys. Res. 1982, 87, 457-468. [CrossRef]

7. Kostense, J.K. Measurements of surf beat and set-down beneath wave groups. In Proceedings of the 19th International Conference on Coastal Engineering, Houston, TX, USA, 3-7 September 1984; pp. 724-740.

8. Baldock, T.E.; Huntley, D.A.; Bird, P.A.D.; O'Hare, T.J.; Bullock, G.N. Breakpoint generated surf beat induced by bichromatic wave groups. Coast. Eng. 2000, 39, 213-242. [CrossRef]

9. Symonds, G.; Huntley, D.A.; Bowen, A.J. Two-dimensional surf beat: Long wave generation by a time-varying breakpoint. J. Geophys. Res. 1982, 87, 492-498. [CrossRef]

10. Schaffer, H.A. Infragravity waves induced by short wave groups. J. Fluid Mech. 1993, 247, 551-588. [CrossRef]

11. Alsina, J.M.; Padilla, E.M.; Cáceres, I. Sediment transport and beach profile evolution induced by bi-chromatic wave groups with different group periods. Coast. Eng. 2016, 114, 325-340. [CrossRef]

12. Dong, G.; Ma, X.; Perlin, M.; Ma, Y.; Yu, B.; Wang, G. Experimental study of long wave generation on sloping bottoms. Coast. Eng. 2009, 56, 82-89. [CrossRef]

13. Baldock, T.E.; Holmes, P.; Horn, D.P. Low frequency swash motion induced by wave grouping. Coast. Eng. 1997, 32, 197-222. [CrossRef]

14. Madsen, P.A.; Sørensen, H.A.; Schaffer, H.A. Surf zone dynamics simulated by a Boussinesq-type model. Part I. Model description and cross-shore motion of regular waves. Coast. Eng. 1997, 32, 255-287. [CrossRef]

15. Madsen, P.A.; Sørensen, O.R.; Schäffer, H.A. Surf zone dynamics simulated by a Boussinesq type model. Part II. surf beat and swash oscillations for wave groups and irregular waves. Coast. Eng. 1997, 32, $289-319$. [CrossRef] 
16. Padilla, E.M.; Alsina, J.M. Laboratory experiments of bichromatic wave groups propagation on a gentle slope beach profile and energy transfer to low and high frequency components. In Proceedings of the 35th Conference on Coastal Engineering, Antalya, Turkey, 17-20 November 2016.

17. Roelvink, J.A.; Stive, M.J.F. Bar-generating cross-shore flow mechanisms on a beach. J. Geophys. Res. 1989, 94, 4785-4800. [CrossRef]

18. Roelvink, J.A. Surf Beat and Its Effect on Cross-Shore Profiles. Ph.D. Thesis, TU Delft, Delft, The Netherlands, 1993.

19. Jannat, M.R.A.; Asano, T. External forces of sediment transport in surf and swash zones induced by wave groups and their associated long waves. Coast. Eng. 2007, 49, 205-227. [CrossRef]

20. Kobayashi, N.; Otta, A.K.; Roy, I. Wave reflection and run-up on rough slopes. J. Water, Port Coast. Ocean Eng. ASCE 1987, 113, 282-298. [CrossRef]

21. Halfiani, V.; Ramli, M. Deformation of bichromatic wave groups based on third order side band solution of Benjamin-Bona-Mahony equation. J. Phys. Conf. Ser. 2017, 890, 012011. [CrossRef]

22. Longuet-Higgins, M.S. Breaking waves in deep or shallow water. In Proceedings of the 10th Conference on Naval Hydrodynamics, Cambridge, MA, USA, 24-28 June 1974; pp. 597-605.

23. Rapp, R.J.; Melville, W.K. Laboratory measurements for deep water breaking waves. Philos. Trans. R. Soc. Lond. A 1990, 331, 735-800. [CrossRef]

24. Baldock, T.E.; Swan, C.; Taylor, P.H. A laboratory study of nonlinear surface waves on water. Philos. Trans. R. Soc. Lond. A 1996, 354, 649-676. [CrossRef]

25. Barnes, T. The Generation of Low-Frequency Water Waves on Beaches. Ph.D. Thesis, University of Bristol, Bristol, UK, 1996.

26. Johannessen, T.; Swan, C. A laboratory study of the focusing of transient and directionally spread surface water waves. Proc. R. Soc. Lond. A 2001, 457, 971-1006. [CrossRef]

27. Sun, Y.; Zhang, X. A second order analytical solution of focused wave group interacting with a vertical wall. Int. J. Nav. Arch. Ocean Eng. 2017, 9, 160-176. [CrossRef]

28. Vyzikas, T.; Stagonas, D.; Buldakov, E.; Greaves, D. The evolution of free and bound waves during dispersive focusing in a numerical and physical flume. Coast. Eng. 2018, 132, 95-109. [CrossRef]

29. Borthwick, A.G.L.; Hunt, A.C.; Feng, T.; Taylor, P.H.; Stansby, P.K. Flow kinematics of focused wave groups on a plane beach in the U.K. Coastal Research Facility. Coast. Eng. 2006, 53, 1033-1044. [CrossRef]

30. Dally, W.R. Long wave effects in laboratory studies of cross-shore transport. In Proceedings of the Special Conference on Quantitative Approaches to Coastal Sediment Processes, Seattle, WA, USA, 25-27 June 1991; American Society of Civil Engineers: Reston, VA, USA, 1991; pp. 85-99.

31. Brocchini, M.; Bellotti, G. Integral flow properties of the swash zone and averaging. Part 2. Shoreline boundary conditions for wave-averaged models. J. Fluid Mech. 2002, 458, 269-281. [CrossRef]

32. Baldock, T.E.; Manoonvoravong, P.; Pham, K.S. Beach face morphology and surf beat sediment transport. J. Coast. Res. 2007, 50, 631-635.

33. Baldock, T.E.; Manoonvoravong, P.; Pham, K.S. Sediment transport and beach morphodynamics induced by free long waves, bound long waves and wave groups. Coast. Eng. 2010, 57, 898-916. [CrossRef]

34. Vicinanza, D.; Baldock, T.E.; Contestabile, P.; Alsina, J.; Cáceres, I.; Brocchini, M.; Conley, D.; Andersen, T.L.; Frigaard, P.; Ciavola, P. Swash Zone Response Under Grouping Storm Conditions. J. Hydraul. Res. 2011, 4, 55-63. [CrossRef]

35. Cáceres, I.; Alsina, J.M.; Sánchez-Arcilla, A. Mobile bed experiments focused to study the swash zone evolution. J. Coast. Res. 2009, 56, 1736-1740.

36. Kai, Y.; Rushu, R.; Liang, W. Beach profile change under varying wave climates. Coast. Eng. 1988, 1535-1543. [CrossRef]

37. Li, Y.; Raichlen, F. Non-breaking and breaking solitary wave run-up. J. Fluid Mech. 2002, 456, $295-318$. [CrossRef]

38. Dette, H.H.; Peters, K.; Newe, J. Large Wave Flume Experiments '96/97, Experiments on Beach and Dune Stability; Braunschweig University of Technology: Braunschweig, Germany, 1998; Volume 830. 
39. Tomasicchio, G.R.; Frega, F. Velocity profiles at the swash zone. In Proceedings of the Coastal Structures 2003, Portland, OR, USA, 26-30 August 2003; American Society of Civil Engineers: Reston, VA, USA, 2004; Volume 1, pp. 715-727.

40. Blenkinsopp, C.E.; Turner, I.L.; Masselink, G.; Russell, P.E. Swash zone sediment fluxes: Field observations. Coast. Eng. 2011, 58, 28-44. [CrossRef]

41. Molloy, E. Seiching in Cockburn Sound. Master's Thesis, Department of Environmental Engineering, University of Western Australia, Crawley, Australia, 2001.

42. Rabinovich, A.B. Seiches and Harbor Oscillations. Handbook of Coastal and Ocean Engineering; Kim, Y.C., Ed.; World Scientific Publ.: Singapore, 2009.

43. Merian, J.R. Ueber die Bewegung tropfbarer Flüssigkeiten in Gefässen [On the Motion of Drippable Liquids in Containers]. Ph.D. Thesis, Schweighauser, Basel, Switzerland, 1828; OCLC 46229431. (In German)

44. Wilson, B. Seiches. Adv. Hydrosci. 1972, 8, 1-94.

45. Kirby, J.T.; Özkan-Haller, H.T.; Haller, M.C. Seiching in a large wave flume. In Proceedings of the 30th International Conference on Coastal Engineering, San Diego, CA, USA, 3-8 September 2006; pp. $63-67$.

46. Maddux, T.B.; Cowen, E.A.; Foster, D.L.; Haller, M.C.; Stanton, T.P. The Cross-shore sediment transport experiment (CROSSTEX). Coast. Eng. 2007, 5, 2547-2559.

47. Benassai, G.; Aucelli, P.; Budillon, G.; de Stefano, M.; di Luccio, D.; di Paola, G.; Montella, R.; Mucerino, L.; Sica, M.; Pennetta, M. Rip current evidence by hydrodynamic simulations, bathymetric surveys and UAV observation. Nat. Hazards Earth Syst. Sci. 2017, 17, 1493-2017. [CrossRef]

48. Nunziata, F.; Migliaccio, M.; Li, X.; Ding, X. Coastline extraction using dual-polarimetric COSMO-SkyMed PingPong mode SAR data. IEEE Geosci. Remote Sens. Lett. 2014, 11, 104-108. [CrossRef]

49. Nunziata, F.; Buono, A.; Migliaccio, M.; Benassai, G. An Effective Method to Extract Coastline from Dual-Polarimetric C- and X-Band SAR Measurements; European Space Agency (Special Publication) ESA SP, SP-740; European Space Agency (ESA): Paris, France, 2016.

50. Benassai, G.; Migliaccio, M.; Montuori, A. Sea wave numerical simulations with COSMO-SkyMed@ SAR data. J. Coast. Res. 2013, 65, 660-665. [CrossRef]

51. Riefolo, L.; Azzellino, A.; Ferrante, V.; Contestabile, P.; Vicinanza, D. Wave flume-generated seiching analysis. In Proceedings of the Twenty-Fifth International Ocean and Polar Engineering Conference ISOPE, Kona, HI, USA, 21-26 June 2015; pp. 559-566.

52. Riefolo, L.; Contestabile, P.; Dentale, F.; Benassai, G. Low frequency waves detected in a large wave flume under irregular waves with different grouping factor and combination of regular waves. Water 2018, 10, 228. [CrossRef]

53. Longuet-Higgins, M.S.; Stewart, R.W. Radiation stress and mass transport in gravity waves, with application to surf beats. J. Fluid Mech. 1962, 13, 481-504. [CrossRef]

54. Longuet-Higgins, M.S.; Stewart, R.W. Radiation stresses in water waves: A physical discussion, with applications. Deep-Sea Res. 1964, 11, 259-562. [CrossRef]

55. Watson, G.; Barnes, T.C.D.; Peregrine, D.H. The generation of low-frequency waves by a single wave group incident on a beach. Coast. Eng. 1994, 1995, 776-790.

56. Mase, H. Frequency down-shift on swash oscillations compared to incident waves. J. Hydraul. Res. 1995, 33, 397-411. [CrossRef]

57. Ciavola, P.; Vicinanza, D.; Fontana, E. Beach drainage as a form of shoreline stabilization: Case studies in Italy. In Proceedings of the 31st International Conference on Coastal Engineering, Hamburg, Germany, 31 August-5 September 2008.

58. Ciavola, P.; Vicinanza, D.; Aristodemo, F.; Contestabile, P. Large-scale morphodynamic experiments on a Beach Drainage System. J. Hydraul. Res. 2011, 49, 523-528. [CrossRef]

59. Damiani, L.; Aristodemo, F.; Saponieri, A.; Verbeni, B.; Veltri, P.; Vicinanza, D. Full-scale experiments on a beach drainage system: Hydrodynamic effects inside beach. J. Hydraul. Res. 2011, 49, 44-54. [CrossRef]

60. Contestabile, P.; Aristodemo, F.; Vicinanza, D.; Ciavola, P. Laboratory study on a beach drainage system. Coast. Eng. 2012, 66, 50-64. [CrossRef]

61. Ciavola, P.; Contestabile, P.; Aristodemo, F.; Vicinanza, D. Beach sediment mixing under drained and undrained conditions. J. Coast. Res. 2013, 65, 1503-1508. [CrossRef] 
62. Russell, P.E. Mechanisms for beach erosion during storms. Cont. Shelf Res. 1993, 13, 1243-1265. [CrossRef]

63. Smith, G.G.; Mocke, G.P. Interaction between breaking/broken waves and infragravity-scale phenomena to control sediment suspension transport in the surf zone. Mar. Geol. 2002, 187, 329-345. [CrossRef]

(c)

(C) 2018 by the authors. Licensee MDPI, Basel, Switzerland. This article is an open access article distributed under the terms and conditions of the Creative Commons Attribution (CC BY) license (http:/ / creativecommons.org/licenses/by/4.0/). 